\title{
THE
}

\section{Living in the big city: preference for broad substrates results in niche expansion for urban Anolis lizards}

\author{
Andrew C. Battles \\ University of Rhode Island \\ Malcolm Moniz \\ University of Rhode Island \\ Jason J. Kolbe \\ University of Rhode Island, jjkolbe@uri.edu
}

Follow this and additional works at: https://digitalcommons.uri.edu/bio_facpubs

The University of Rhode Island Faculty have made this article openly available.

Please let us know how Open Access to this research benefits you.

This is a pre-publication author manuscript of the final, published article.

Terms of Use

This article is made available under the terms and conditions applicable towards Open Access

Policy Articles, as set forth in our Terms of Use.

Citation/Publisher Attribution

Battles, A.C., Moniz, M. \& Kolbe, J.J. Urban Ecosyst (2018) 21: 1087. https://doi.org/10.1007/

s11252-018-0787-1

Available at: https://doi.org/10.1007/s11252-018-0787-1 
1 Title: Living in the big city: preference for broad substrates results in niche expansion for urban

2 Anolis lizards

3 Authors: Andrew C. Battles, Malcom Moniz, Jason J. Kolbe

4 Institute: University of Rhode Island, 120 Flagg Rd., Kingston, RI 02881 (USA)

5 Corresponding Author: Andrew Battles

6 817-975-5731, andrewcbattles@gmail.com, ORC ID: 0000-0002-9063-7747

7 Keywords: Anolis cristatellus, Anolis sagrei, Miami, anole, structural habitat niche, perch

8 preference 


\section{ABSTRACT}

Persistence of animals in urban habitats, a stark environmental contrast to natural habitats, can be explained through evaluating the mechanisms behind organism-habitat interactions. One of the most notable effects of urbanization is the change in structural habitat; vegetation is removed and modified, favoring large trees and adding artificial structures in cities, which may alter how organismal preferences for aspects of the habitat are realized. We evaluated the mechanisms by which structural habitat changes associated with urbanization alter the available vegetation and substrates on which two species of Anolis lizards perch in urban and natural forest sites in Miami, FL. We also experimentally assessed habitat preference in the lab to establish the mechanism behind habitat selection. We found that vegetation was broader in urban areas compared to natural habitats, and artificial structures in urban areas were more than twice the diameter of available natural perches. Lizards expressed their preference for broad perches by selecting broader vegetation and artificial structures compared to their availability in both habitats. With the increased availability of broad substrates in urban areas, perch diameters selected by lizards resulted in an expansion of this aspect of the structural habitat niche for both species. The two species differed, however, in other responses to altered urban habitats. Anolis cristatellus tended to avoid artificial substrates, whereas A. sagrei used both natural and artificial structures in proportion to their availabilities. This study provides a mechanistic explanation for how urbanization alters structural habitats, leading to niche expansion for organisms living in cities.

\section{INTRODUCTION}

Most species alive today have an evolutionary history that includes persisting through environmental changes and encountering novel habitats to some degree (Thompson, 2013). 
32 However, ongoing human-induced rapid environmental change (HIREC) is unprecedented in

33 both its rate and magnitude of environmental change on this planet (Palumbi, 2001; Hobbs et al.,

34 2006; Sih et al., 2011; Barnosky et al., 2012). Local extinctions and range shifts demonstrate that

35 some organisms are unable to respond successfully in situ to HIREC (Lynch and Lande, 1993;

36 McKinney and Lockwood, 1999; Brook et al., 2008; Estrada et al., 2015). In contrast, other

37 species persist, and some even thrive, when encountering novel environments produced by

38 human activities (Kowarik 2011; Lowry et al., 2013). To better understand how changing

39 environmental conditions challenge the persistence of populations, we need mechanistic studies

40 that quantify changes in niche dimensions due to global change (Shochat et al. 2006; Sol et al.

41 2013). Such studies should evaluate changes in resource availability in altered habitats, how

42 organisms respond through their resource use and preferences, and if individuals experience any

43 fitness consequences. This niche-based assessment should yield valuable insight into the role of

44 niche dynamics (e.g. niche contraction or niche expansion) in determining whether populations

45 persist under HIREC (Wingfield et al., 2011).

Urbanization likely alters the niche space available in cities, ultimately determining

47 whether or not populations persist there, yet we know little about the underlying dynamics of

48 how organisms respond to this change. During urbanization, natural vegetation is removed and

49 replaced with novel artificial structures (e.g. walls, pavement, and lamp posts) and managed

50 vegetation assemblages (McDonnell and Pickett, 1990; Forman, 2014; McDonnell and Hahs,

51 2015). Habitat changes in cities occur at rates far greater than in natural habitats and in some

52 cases, elicit phenotypic responses distinct from those observed in natural habitats (Winchell et

53 al., 2016; Alberti et al., 2017). These and other selection pressures in urban areas may promote

54 adaptive evolution in traits that improve fitness in cities (Nemeth and Brumm 2009; Atwell et al. 
2012; Donihue and Lambert 2014; Weaving et al. 2016; Winchell et al. 2016).New resources in urban habitats may benefit species with adaptations that happen to be useful in urban habitats (i.e. pre-adaptation; McDonnell and Hahs, 2015), and previous studies show that urban animal populations exploit a variety of anthropogenic resources (Lowry et al., 2013; Oro et al., 2013; Penick et al., 2015). If urban habitats increase the availability of habitat elements preferred by an organism, urban populations may experience a realized niche expansion (Pearman et al. 2008). A more mechanistic, niche-focused framework that includes organismal preferences, organism-habitat interactions, and comparison of habitat differences between urban and natural environments is needed.

A key axis of diversification for Anolis lizards is the structural habitat - the diameter, height, and type of vegetation used by perching lizards (Losos, 2009), and strong habitat useperformance relationships drive habitat selection in many species (Rodríguez-Robles et al. 2005; Johnson et al. 2006). Anole structural habitat use varies interspecifically, intraspecifically, and in different environments (Irschick et al., 2005a,b). Furthermore, anole habitat selection is correlated with locomotor performance, a commonly used fitness proxy in anoles (Irschick and Losos 1999; Losos 2009; Gilman and Irschick 2013; Irschick and Higham 2016). Numerous Anolis species are found in urban and natural habitats in their native and non-native ranges (Irschick et al. 2005a,b; Marnocha et al. 2011; Kolbe et al. 2016a; Winchell et al. 2016). Two Anolis species found in Miami, FL, USA, Anolis cristatellus and Anolis sagrei, are ideal for evaluating how the habitat alterations caused by urbanization influence structural habitat preferences and selection. Both species inhabit urban and natural forest habitats that occur in close proximity to each other. In their natural forest habitats, these species are commonly found 
77 on trunks, branches, leaves, and the ground, making them likely to be sensitive to the structural

78 habitat changes associated with urbanization.

In this study, we first compared the structural habitat availability and use by lizards in

80 natural forests and urban areas. This allowed us to evaluate whether lizards are selecting aspects

81 of the structural habitat and if urbanization alters these relationships. After comparing

82 availability, use, and selection in the field, we evaluated preference for a key aspect of the

83 structural habitat - perch diameter - using a laboratory experiment. We predict that urban areas

84 will contain a greater proportion of broad substrates than natural areas due to the removal of

85 smaller trees, branches, and woody debris in urban areas and the addition of artificial substrates,

86 such as walls and posts. We expect that lizards will prefer larger-diameter perches and non-

87 randomly select wide perches compared to their availability, leading to an expansion of the

88 structural habitat niche in urban sites. Results from our study identify mechanisms behind

89 patterns of organismal responses to urbanization that should improve predictions regarding

90 species and population persistence in our increasingly urbanized world.

91 METHODS

\section{Study species and study sites}

We studied two species of Anolis, small insectivorous lizards found naturally in southern

94 North America, Central and South America, and throughout the Caribbean (Losos, 2009).

95 Several Anolis species have been introduced to the Miami metropolitan area (Kolbe et al., 2007),

96 two of which are common in both natural forest and urban areas. Anolis sagrei is native to Cuba

97 and the Bahamas, and non-native populations are now widely distributed in the southeastern

98 United States with Miami area populations dating to the 1940-60s (Bell 1953; Salzburg 1984;

99 Kolbe et al. 2004). Anolis cristatellus is native to Puerto Rico, and was first documented in 
Miami in the mid-1970s (Wilson and Porras 1983; Powell et al. 1996; Bartlett and Bartlett 1999; Kolbe et al. 2007). In contrast to the nearly ubiquitous $A$. sagrei, the distribution of $A$. cristatellus is more restricted, radiating out from two independent points of introductions in the Miami area (Kolbe et al. 2016b). Both A. sagrei and A. cristatellus are classified as trunk-ground habitat specialists, meaning they commonly occupy the ground and perches up to $\sim 2 \mathrm{~m}$ (Salzburg 1984; Losos 2009). The larger A. cristatellus (snout-vent length, or SVL, up to $75 \mathrm{~mm}$ in males and $60 \mathrm{~mm}$ in females; mean mass is $8.5 \mathrm{~g}$ in males) typically perches higher than the smaller and more terrestrial $A$. sagrei (SVL up to $69 \mathrm{~mm}$ in males and $55 \mathrm{~mm}$ in females; mean mass is $4.8 \mathrm{~g}$ in males).

We studied lizards in four urban and four natural sites throughout the Miami metropolitan area between May and August in 2014. Generally, natural sites were closed-canopy forests on upland hammocks, consisting of hardwood-oak overstory canopy with palmettos and saplings in the understory, and were forest patches within the urban matrix of metropolitan Miami. Urban sites were located within human-altered areas, generally along roadsides with bike paths, canals, and sidewalks. We are unaware of any urban sites in Miami that contain only A. cristatellus. Refer to supplementary materials for detailed descriptions of study sites.

\section{Habitat availability, use and selection}

Because structural habitat is a key niche axis for anoles, we evaluated the impact of urbanization on the availability of perch sites and perch use by lizards. To understand the relationship between perch availability and the perch use, we conducted habitat availability transects to quantify the differences between urban and natural sites, and then compared these availabilities to lizard habitat use. We measured the diameter $(\mathrm{cm})$, height $(\mathrm{cm})$, and substrate type of potential lizard perches, denoted further as habitat availability, which includes artificial 
123 substrates in urban sites. At all sites, we measured available vegetation (and structures in urban 124 areas) at $0.25 \mathrm{~m}$ intervals, from $0-2 \mathrm{~m}$ vertically. Trunk-ground ecomorphs such as the two 125 Anolis species in this study rarely perch higher than $2 \mathrm{~m}$ (Losos, 2009). We measured one 126 potential perch at each height, within a $0.5-\mathrm{m}$ radius of the sample point. We followed perches 127 that continued outside of the $0.5-\mathrm{m}$ radius but that originated from within it. If a particular height 128 did not have an available perch, such as when vegetation was $<2 \mathrm{~m}$ (e.g. a low bush), we did not 129 record data at that height. Some transect points had no vegetation within a $0.5 \mathrm{~m}$ radius, and in 130 these cases no data were recorded for any height; these were considered 'open ground' and used 131 to analyze percent open space. We did not include walls in the perch diameter analyses because 132 we are uncertain on how to quantify accurately these surfaces; very large diameters would skew 133 the results and capping measurements would be inaccurate. Because urban sites were usually 134 along a road, we conducted 6-8 m transects every 30-50 m perpendicular to the road. Exact 135 transect lengths and intervals between transects depended on the length of the site and the 136 distance between the road and the edge, such as the canal edge or building. In natural sites, we 137 conducted two separate transects beginning from haphazard locations within the study plots that 138 followed a random compass heading. Each transect was approximately $20 \mathrm{~m}$ in length, with 6-m 139 perpendicular transects at 5-m intervals along the main transect. We collected roughly 2-3 times 140 as many habitat availability observations (not including transect points without vegetation) as 141 lizard perch use observations at each site.

142 We compared vegetation availabilities to perch use by lizards in the urban and natural 143 sites to determine habitat selection. Using a telescopic pole with a noose, we captured 144 undisturbed adult lizards over a period of 2-5 days in each site and recorded sex, species, and 145 SVL as well as the diameter, height, and substrate of the location where each lizard was perched. 
146 Before releasing each lizard, we marked it with a small dot using white-out to ensure we did not

147 re-capture the same individual during the study. We expended equal capture effort in all sites to

148 ensure that we captured a representative sample of the population. We captured males and

149 females totaling approximately 120 adult lizards per species per site (male and female sample

150 sizes in table S1), evenly collected throughout their activity time during the day (0700 to 1800

$151 \mathrm{hrs}$ ), and never in inclement weather.

152 Habitat preference

153 To measure perch-diameter preference, we collected 20 male $A$. sagrei and 20 male $A$.

154 cristatellus from natural sites and shipped them to the University of Rhode Island (Kingston, RI).

155 In a $1.8 \mathrm{~m} \times 1.8 \mathrm{~m} \times 1.8 \mathrm{~m}$ mesh enclosure in the lab, lit with overhead fluorescent lights

156 approximately $3 \mathrm{~m}$ above the floor (and no lights or heat sources for basking), we presented

157 individual lizards a choice of six perches (i.e., tree trunks, $1.6 \mathrm{~m}$ high) in three duplicated

158 diameters of 2,7 , and $12 \mathrm{~cm}$. These sizes cover the range of mean vegetation diameters observed

159 for availability and use by both species in urban and natural habitats. After a two-minute

160 acclimation period under an opaque cover, lizards were given 15 minutes to explore the perches.

161 We recorded the proportion of time spent on each perch compared to the total time lizards were

162 on a perch. Lizards usually selected a perch within the first two minutes, sometimes moving

163 between several perches. We arranged the perches in alternating sizes in a circle. Before each

164 trial, we randomized the location of perches in the circle to eliminate a location effect. Each

165 lizard went through the preference experiment two times. Some lizards never selected a perch

166 and were removed from the analysis (A. sagrei $\mathrm{N}=1$, A. cristatellus $\mathrm{N}=4)$; sample sizes in

167 Table S1.

168 Statistical Analyses 
We performed all statistical analyses in R (R Core Team, 2015), and analyzed species

170

171

172

173

174

175

176

177

178

179

180

181

182

183

184

185

186

187

188

189

190

191

separately for all statistical tests. We compared mean available vegetation diameters of all sites, nested within their site type (urban and natural), using an analysis of variance (ANOVA). We used ANOVA to test for a difference in diameter among vegetation in natural areas, vegetation in urban areas, and artificial structures in urban areas, for both availability and use by males and females. We compared diameters of available substrates (i.e., vegetation and artificial structures) and perch use by sex and site type (urban and natural) with an ANOVA. We also used ANOVA to test for differences in perch height use by sex and site, but did not include availability because nearly all heights were available at each site. To compare the distributions of diameters of available substrates and perches used by lizards between natural and urban environments, we used two-sample Kolmogorov-Smirnov tests. We used Simpson's index of diversity to calculate the diversity of perches used by each species and sex in both site types; values range from 0 (no diversity) to 1 (infinite diversity). We used chi-squared tests to compare the proportion of artificial and natural perches available in urban habitats to the proportion used by lizards, separately by sex. For all tests, lizards were only compared to availability in the sites that they were found (e.g. A. cristatellus for only two of the four urban sites where it was present).

We assessed perch diameter preference from the laboratory experiment using a multinomial mixed model, which accounts for the non-independence of response values, with lizard ID as a random effect to avoid pseudoreplication, and compared the proportions of time spent on small, medium, and large perches for both trials combined using the MCMCglmm package (Hadfield, 2010). The model runs Markov chain Monte Carlo iterations to generate posterior distributions of the response levels. In this case, the mean distributions for time spent on medium and small perches are each compared to time spent on the large perch. 


\section{RESULTS}

\section{Habitat Availability}

Urban sites had broader substrates available than natural sites $\left(F_{1,6}=154.33, p<0.0001\right.$, 195 Figs. 1a, S2); within natural sites, Montgomery and Matheson had narrower vegetation than 196 Barnes $\left(F_{6,2816}=3.26, p<0.01\right)$. Larger mean diameters in urban areas were due to both broader

197 vegetation in urban sites as compared to natural areas and the addition of even broader artificial 198 substrates in urban sites $\left(F_{2,2896}=165.7, p<0.0001\right.$, Fig. 1a). These large differences in 199 vegetation and substrate diameters existed despite not including measurements for walls, which 200 account for about $3 \%$ of availability in urban areas. The distribution of available substrates in 201 urban areas was shifted away from smaller diameters and toward larger ones compared to natural 202 areas $(D=0.23, p<0.0001$, Fig. S2). In most instances, the full range of potential perch heights 203 from the ground to at least $2 \mathrm{~m}$ was available in both natural and urban sites. Urban habitats also 204 had more open ground than natural areas; about half of the urban survey points lacked vegetation 205 (Fig. 2a, Table S2). Urban habitats had a greater variety of potential perches due to the addition 206 of artificial substrates, such as poles, posts, and walls (Fig. 3), which accounted for about 25\% of 207 available substrates (Fig. 2b). Overall, urban areas had broader substrates available (both 208 vegetation and artificial structures) and more open space compared to natural habitats. 


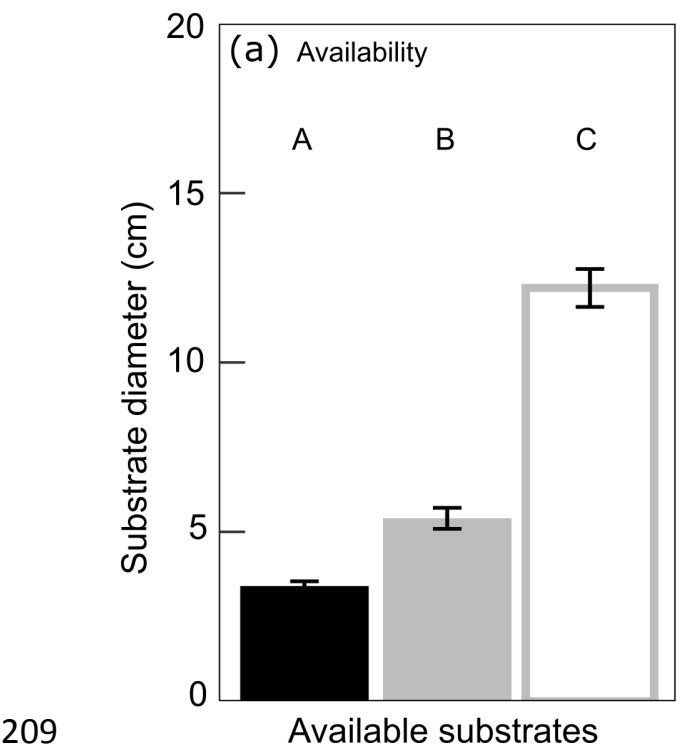

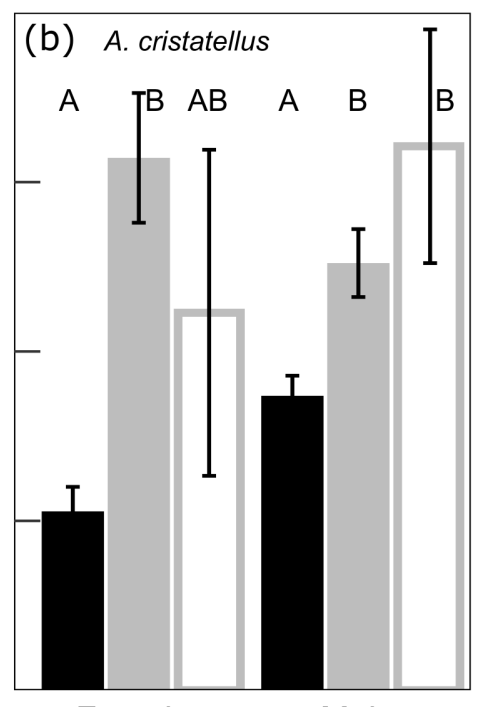

Female

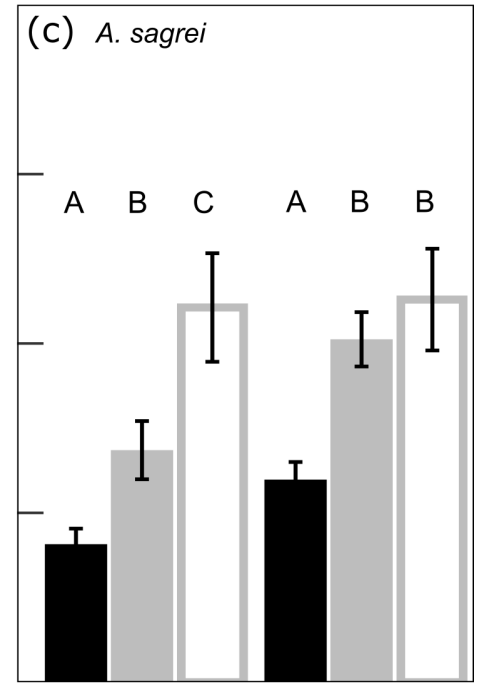

Female

Male

210 Fig. 1 Mean $( \pm \mathrm{SE})$ for diameters of a) available vegetation and artificial substrates in natural and

211 urban sites, b) perches used by $A$. cristatellus, and c) perches used by $A$. sagrei. Vegetation at

212 natural sites is in black, vegetation at urban sites in grey, and artificial substrates in white, with

213 letters indicating significant differences $(P<0.05)$. 


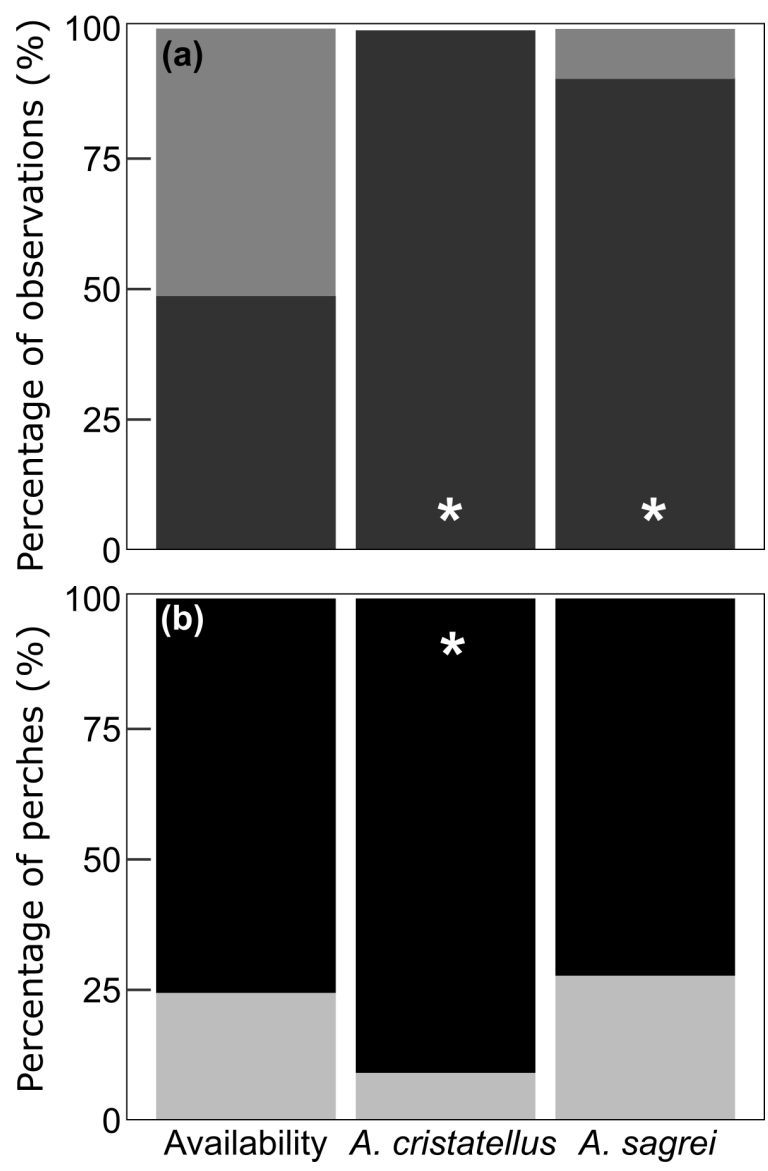

215 Fig. 2 Panel a) shows the proportion of total observations from habitat availability transects that

216 were open ground (light grey) versus vegetation (i.e., potential perches, dark grey) and the

217 proportion of the time lizards used perches (dark grey) compared to the ground (light grey)

218 (Table S2). Panel b) shows the percentage of natural (black) versus artificial (grey) substrates

219 available and perches used by lizards in urban sites. Sites with and without $A$. cristatellus did not

220 differ in availability/use comparisons and so are pooled for availability columns, and female and

221 male perch use did not differ significantly for either species and were pooled for this figure. *

222 indicates $P<0.05$ for the chi-squared test of availability versus perch use by lizards. 


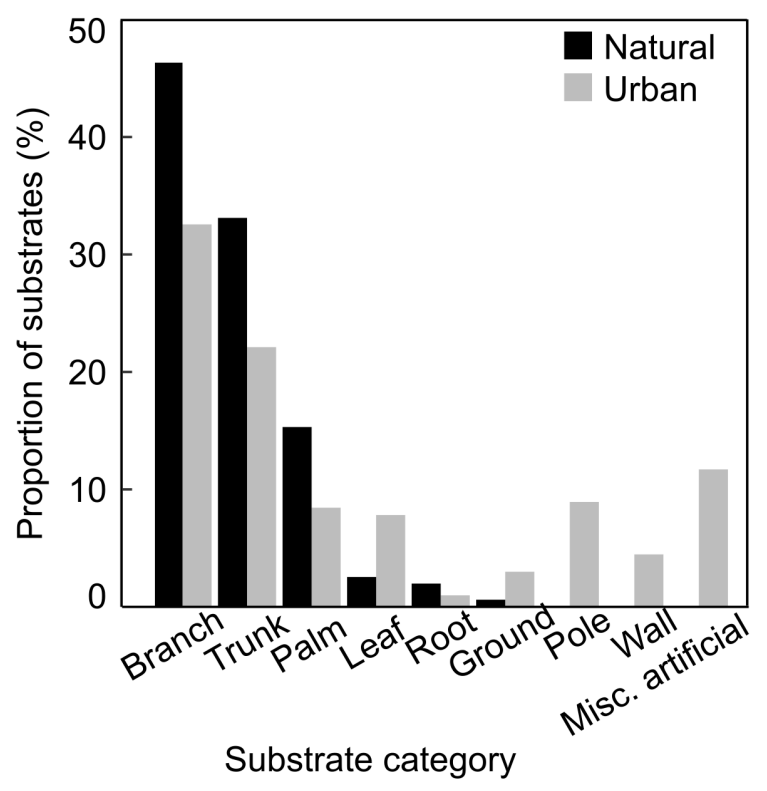

224 Fig. 3 Frequency of natural and artificial substrate availability at natural forest (black) and urban 225 (grey) sites.

226

\section{Habitat Selection}

Despite the ubiquity of open ground in urban habitats, lizards were almost always found on vegetation or artificial structures (Fig. 2a). Lizards used wider perches in urban compared to natural areas, and they selected wider perches than were available in both areas (A. cristatellus: $F_{5,1914}=55.657, p<0.001$, Figs. $1,4 \mathrm{a} ;$ A. sagrei: $F_{5,2841}=31.435, p<0.001$, Figs. $\left.1,4 \mathrm{~b}\right)$.

Lizards also used a greater diversity of perches in urban compared to natural areas (Table 1, Figs. S2, S3). The use of broader perches in urban areas was driven by lizards selecting both wider vegetation, which was almost always wider than vegetation used for perching in natural areas, and artificial substrates, which were over twice the diameter of vegetation in urban areas ( $A$. cristatellus: $F_{5,517}=10.27, p<0.001$, Fig. $1 b$; A. sagrei: $F_{5,714}=9.675, p<0.001$, Fig. $\left.1 \mathrm{c}\right)$. Neither sex of $A$. cristatellus differed in perch height use between urban and natural sites, but females perched lower than males within both sites $\left(F_{3,523}=9.152, p<0.0001\right.$, Figs. $\left.4 \mathrm{a}, \mathrm{S} 1\right)$. Male and female $A$. sagrei perched lower in urban areas than in natural areas and females always 
239 perched lower than males $\left(F_{3,775}=25.53, p<0.0001\right.$, Figs. $\left.4 b, \mathrm{~S} 1\right)$. Both sexes of $A$. sagrei used 240 artificial perches at the same frequency as their availability, but female and male $A$. cristatellus 241 used artificial perches at a lower rate (female: $X^{2}=6.80, \mathrm{df}=1, p<0.001$; male: $X^{2}=4.93$, $\mathrm{df}=1$, $242 p<0.03$, Fig. 2b), suggesting avoidance of artificial substrates by A. cristatellus in Miami.

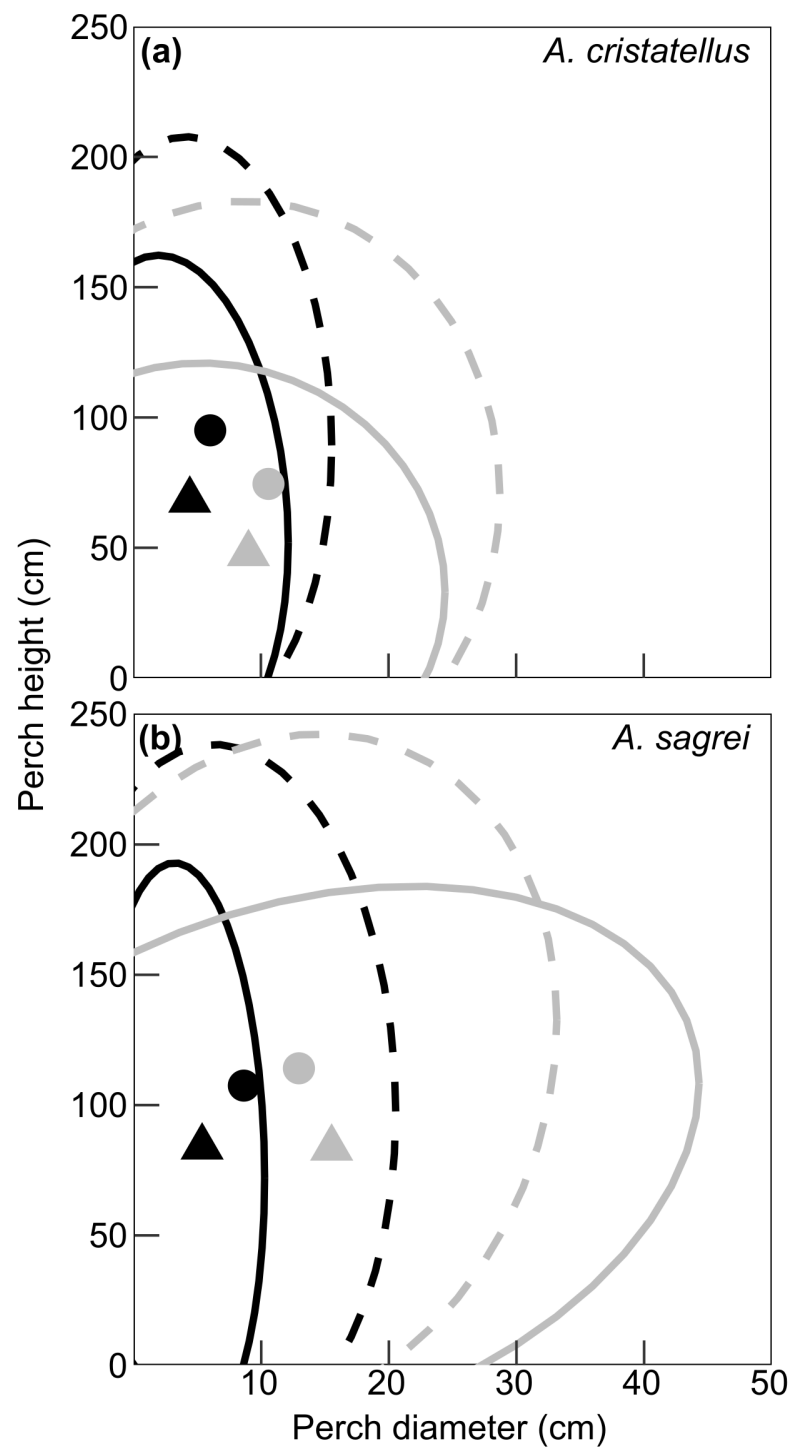

244 Fig. 4 Urban niche expansion of structural habitat use by a) A. cristatellus and b) A. sagrei. Plots 245 of perch diameter against perch height show means (S.E. error bars do not exceed shape size) 246 and 95\% confidence ellipses, separate for males (circles, dashed ellipses) and females (triangles, 247 solid ellipses). Natural sites are in black and urban sites in grey. 
248 Table 1. Simpson's index of diversity for the perch diameter classes used by male and female $A$.

249 cristatellus and A. sagrei and the Kolmogorov-Smirnov distances, indicating the maximum

250 difference between cumulative distribution functions (Fig. S3), significance at $p<0.01$ between

251 distributions in natural and urban sites shown in bold.

252

\begin{tabular}{lllll} 
Species & Sex & $\begin{array}{l}\text { Natural site diameter } \\
\text { diversity (Simpson's D) }\end{array}$ & $\begin{array}{l}\text { Urban site diameter } \\
\text { diversity (Simpson's D) }\end{array}$ & $\begin{array}{l}\text { K-S } \\
\text { dist. }\end{array}$ \\
\hline A. cristatellus & F & 0.42 & 0.62 & $\mathbf{0 . 4 0}$ \\
A. Sagrei & M & 0.71 & 0.76 & $\mathbf{0 . 2 1}$ \\
& F & 0.40 & 0.62 & $\mathbf{0 . 2 2}$ \\
& M & 0.54 & 0.76 & $\mathbf{0 . 2 2}$
\end{tabular}

254 Habitat Preference

255 In the experimental perch preference trials, A. cristatellus and A. sagrei spent an average 256 of $53.1 \%$ and $66.0 \%$ of their time, respectively, on the largest-diameter perches (Fig. 5). Anolis 257 sagrei exhibited a stronger preference for broad-diameter perches, preferring the largest perches 258 to both small $(p<0.001)$ and medium ones $(p<0.001)$, whereas $A$. cristatellus preferred only the 259 largest to the smallest perches $(p<0.001)$. 


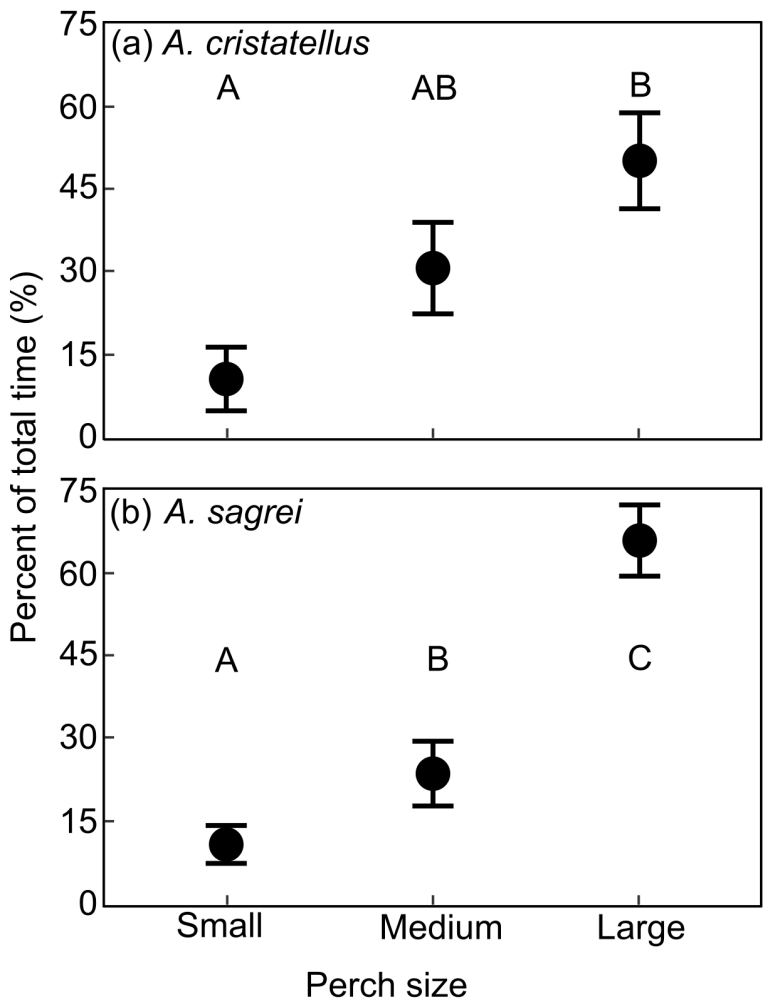

261 Fig. 5 Mean $( \pm$ SE) percentage of total time that a) A. cristatellus and b) A. sagrei spent on small, 262 medium, and large diameter perches during perch preference trials. Letters indicate significant 263 differences $(P<0.01)$, separate for each species.

\section{DISCUSSION}

We found that lizard habitat preferences interact with habitat availability to drive the 266 expansion of the structural habitat niche of anoles in urban areas (Fig. 4). Lizards selected 267 broader diameter vegetation compared to the availability of potential perches in natural habitats 268 (Figs. 1, S1). Urban habitats had broader substrates compared to natural areas due to a 269 combination of broader vegetation and the addition of artificial structures (Fig. 3), and lizards 270 still selected broader perches than available (Figs. 1, S1). Moreover, lizards used a greater diversity of perch diameters in urban sites (Table 1, Fig.

272 S3). Other studies have observed expansion of the realized niche in response to HIREC, 
273 particularly in the context of invasive species responding to novel climates in their non-native

274 range (Holt et al., 2005; Broennimann et al., 2007; Fitzpatrick et al., 2007; Pearman et al., 2008;

275 Tingley et al., 2014), but observations of niche expansion in urban environments are limited.

276 Studies of urbanization tend to focus on population- and community-level responses to habitat

277 alterations, which document changes in abundance and diversity that ultimately emerge as a

278 result of underlying niche dynamics (Aronson et al., 2014; Fischer et al., 2015; Boivin et al.,

279 2016). The broad perches encountered by lizards in urban areas were often artificial substrates

280 (i.e., smooth, vertical surfaces), amounting to roughly one-quarter of available perches (Fig. 2),

281 and lizard locomotor performance has been shown to decrease on smooth, artificial substrates

282 (Kolbe et al. 2016a). Consequently, preference-driven niche expansion in urban areas may result

283 in urban lizards choosing sub-optimal substrates in terms of locomotor performance. The

284 implications of this paradox in cities range from behavioral changes to fitness losses with the

285 potential to alter selective regimes in urban environments (Kolbe et al. 2016a; Winchell et al.

286 2016).

Both Anolis species in our study preferred the largest diameter perches available, with $A$.

288 sagrei having a stronger preference (Fig. 5), which likely results from a strong association

289 between use of broad perches and increased fitness in natural habitats. Sprint speed, a common

290 fitness proxy in anoles, is faster on wider-diameter perches for long-limbed species, such as the

291 two species in this study (Losos and Sinervo, 1989; Irschick and Losos, 1998). Large perches,

292 such as tree trunks, may also confer other fitness benefits. To escape predators, anoles will

293 squirrel, or run to the opposite side of a trunk, placing them out of reach and view of a predator

294 (Cooper, 2006). Further, flight initiation distance, or the distance between a perceived predator

295 and an anole when the anole flees, decreases with increasing perch diameter in five anole species 
296 (Losos and Irschick, 1996), suggesting that the benefits of staying on a perch increase as its

297 diameter increases. Tree trunks typically have fewer nearby branches, thereby increasing

298 visibility. This can increase scanning ability to defend territories, identify prey, find and attract

299 mates, and see predators from farther distances (Johnson et al., 2010). Therefore, for these and

300 possibly other reasons, Anolis species such as these trunk-ground habitat specialists have

301 developed an innate preference for larger-diameter perches in natural habitats.

Preference for larger-diameter perches was consistent with habitat selection by lizards in

303 our study; lizards generally used wider perches than were available in both urban and natural

304 habitats (Figs. 1, S2). Similarly, Wright (2009) found that male and female A. sagrei used

305 broader perches added to their habitats (even though these perches were artificial). In natural

306 habitats in our study, the largest perches were tree trunks and expressing preference for these

307 perches likely confers higher fitness. Because the widest perches available in urban habitats were

308 often artificial (Fig. 1), we would expect both species to occupy broad, artificial structures,

309 especially A. sagrei, which had a stronger preference for large perches (Fig. 5). Indeed, in urban

310 habitats we found $A$. sagrei using natural and artificial perches at rates equivalent to their

311 availability (Fig. 2b), suggesting they do not differentiate between artificial and natural structures

312 per se. In contrast, $A$. cristatellus, which exhibited a weaker preference for broad perches in lab

313 trials and tended to avoid artificial substrates in urban areas, using them roughly $10 \%$ of the time

314 compared to their $22 \%$ availability (Fig. 2 b). While artificial structures certainly contribute to the

315 niche expansion, lizards also select broad vegetation for perching in urban areas (Fig. 1b,c).

316 However, smooth substrates, which are rare or absent in natural habitats, may alter the costs and

317 benefits of using broad perches in urban environments (Kolbe et al. 2016a). 
If artificial structures confer reduced performance, we can think of two primary reasons

why lizards use them without apparent fitness losses. First, behavioral strategies may be used to avoid suboptimal habitat. Anolis crisatellus demonstrates that niche expansion in urban areas can still occur without relying upon artificial substrates (Figs. 1, 2); perch diameter does not differ between artificial and natural perches for this species in urban areas (Fig. 1b). Avoidance of artificial substrates may have occurred because the fitness losses of using artificial substrates are great enough to alter habitat selection cues in urban areas (Schlaepfer et al., 2005). Variation in habitat selection behavior may be adaptive as populations encounter urban environments (Lapiedra et al., 2017). Second, evolutionary adaptation to HIREC, including urbanization, occurs across a wide range of taxa (Nemeth and Brumm, 2009; Atwell et al., 2012; McDonnell and Hahs, 2015), so specific components of the urban habitat, such as substrate composition are likely to be a selective force. For example, Winchell et al. (2016) showed predictable phenotypic differences (i.e., greater relative hindlimb length and more lamellae) between anoles in urban and natural habitats based on habitat characteristics (such as perch diameter) and demonstrated a genetic basis for these differences, which supports adaptation. Kolbe et al. (2016a) found a performance basis for this morphological variation where A. cristatellus with longer limbs proportional to their body size sprinted faster and were more stable on smooth, vertical substrates. Both studies (Kolbe et al. 2016a; Winchell et al. 2016) were conducted in the native range of $A$. cristatellus, where populations have experienced the effects of urbanization for potentially hundreds of generations, whereas the Miami populations in this study were introduced only a few decades ago, so the time exposed to urbanization may influence any potential selective pressures. The extent to which the invasion process alters phenotypes and 
environmental conditions for non-native populations compared to their source populations needs to be explicitly evaluated in future studies.

In this study, we explored mechanisms by which two species of Anolis lizards persist in urban habitats markedly different than their natural habitats, an important task in understanding how HIREC phenomena affect organism-environment interactions (Wingfield et al., 2011). We demonstrated that preference for broad perches and their increased availability in urban habitats interact to facilitate niche expansion of a key component of the structural habitat niche.

However, the broadest perches in urban habitats are artificial structures, which are ecologically novel and could reduce fitness (e.g. reduced locomotor performance in Kolbe et al. 2016a). Several factors may allow lizards to minimize the performance losses associated with artificial substrates and therefore not experience population declines in cities. First, artificial structures, though significantly larger than vegetation in urban areas, are not the sole contributor to niche expansion. Second, lizards may avoid reduced-fitness artificial structures, as A. cristatellus does, suggesting preference cues may shift from substrate diameter to other features, such as surface roughness. Third, morphology may be under selection in urban areas, resulting in increased performance on artificial substrates. This study demonstrates that the consequences of urbanization for one aspect of the ecological niche, but other factors beyond the structural habitat undoubtedly contribute to fitness in urban areas. For example, increased urban temperatures (i.e., the urban heat island effect) likely affect several traits important for fitness of these ectothermic organisms, such as metabolism, activity and performance (Gunderson and Leal, 2012). Urban landscapes provide opportunities for researchers to study how organisms cope with environmental change at relatively accessible scales (e.g. spatial, temporal; McDonnell and Pickett, 1991), increasing the power of predictions for organismal response to future change. 
363 Future studies should follow a mechanistic framework for evaluating influences of other urban

364 habitat changes to better understand what factors contribute to the persistence of species in cities

365 and how those factors interact.

366 ACKNOWLEDGEMENTS

367 We thank the Miami-Dade Parks and Recreation department for permission to use

368 Miami-Dade parks as study sites, Z. Chejanovski and J. Stroud for collecting and shipping

369 lizards, and P. Griffith and the Montgomery Botanical Center for research sites and support. We

370 thank E. Preisser and the Kolbe lab group for helpful comments on drafts on this manuscript.

371 COMPLIANCE WITH ETHICAL STANDARDS

372 Protocols for use of lizards were approved by the URI Institutional Animal Care and Use

373 Committee (AN11-09-005). This work was funded by grants from the National Geographic

374 Society, the National Science Foundation (DEB-1354897), and the University of Rhode Island

375 Enhancement of Graduate Research Award as well as funds from the University of Rhode Island.

376 A. Battles was a National Science Foundation graduate research fellow. M. Moniz participated in

377 the URI Coastal Fellows Program during this project. We can think of no conflicts of interest for

378 this work. 


\section{REFERENCES}

Alberti M, Correa C, Marzluff JM, Hendry AP, Palkovacs EP, \& Gotanda KM, et al. (2017) Global urban signatures of phenotypic change in animal and plant populations, PNAS 114:8951-8956. https://doi.org/10.1073/pnas.1606034114

Aronson MFJ, La Sorte FA, Nilon CH, Katti M, Goddard MA, Lepczyk CA, et al. (2014) A global analysis of the impacts of urbanization on bird and plant diversity reveals key anthropogenic drivers. P Roy Soc B-Biol Sci 281:20133330. https://doi.org/10.1098/rspb.2013.3330

Atwell JW, Cardoso GC, Whittaker DJ, Campbell-Nelson S, Robertson KW, \& Ketterson ED (2012) Boldness behavior and stress physiology in a novel urban environment suggest rapid correlated evolutionary adaptation. Behav Ecol 23:960-969. https://doi.org/10.1093/beheco/ars059

Barnosky, AD, Hadly, EA, Bascompte, J, Berlow, EL, Brown, JH, Fortelius, M, et al (2012) Approaching a state shift in Earth's biosphere. Nature:486, 52-58. https://doi.org/10.1038/nature11018

Bartlett, RD, \& Bartlett, PP (1999) A Field Guide to Texas Reptiles and Amphibians (Vol. 22). Gulf Pub. Co.

Bell, LN (1953) Notes on Three Subspecies of the Lizard Anolis sagrei in Southern Florida. Copeia 63. https://doi.org/10.2307/1440256

Boivin NL, Zeder MA, Fuller DQ, Crowther A, Larson G, Erlandson J. M., ... Petraglia M. D. (2016). Ecological consequences of human niche construction: Examining long-term anthropogenic shaping of global species distributions. PNAS 113:6388-6396. https://doi.org/10.1073/pnas.1525200113 
402

403

404

405

406

407

408

409

410

411

412

413

414

415

416

417

418

419

420

421

422

423

424

Broennimann O, Treier UA, Müller-Schärer H, Thuiller W, Peterson AT, \& Guisan A (2007)

Evidence of climatic niche shift during biological invasion. Ecol Lett 10:701-709 doi:10.1111/j.1461-0248.2007.01060.x. https://doi.org/10.1111/j.1461-0248.2007.01060.x

Brook, BW, Sodhi, NS, \& Bradshaw, CJA (2008) Synergies among extinction drivers under global change. Trends Ecol Evol 23:453-460. https://doi.org/10.1016/j.tree.2008.03.011

Cooper WE (2006) Risk factors affecting escape behaviour by Puerto Rican Anolis lizards. Can J Zool 84:495-504. https://doi.org/10.1139/z06-018

Donihue CM, \& Lambert MR (2014) Adaptive evolution in urban ecosystems. Ambio 44:194203. https://doi.org/10.1007/s13280-014-0547-2

Estrada, A, Meireles, C, Morales-Castilla, I, Poschlod, P, Vieites, D, Araújo, MB, \& Early, R (2015) Species' intrinsic traits inform their range limitations and vulnerability under environmental change. Glob Ecol Biogeogr 24:849-858. https://doi.org/10.1111/geb.12306

Fischer JD, Schneider SC, Ahlers AA, \& Miller JR (2015) Categorizing wildlife responses to urbanization and conservation implications of terminology. Conserv Biol 29:1246-1248. https://doi.org/10.1111/cobi.12451

Fitzpatrick MC, Weltzin JF, Sanders NJ, \& Dunn RR (2007) The biogeography of prediction error: Why does the introduced range of the fire ant over-predict its native range? Global Ecol and Biogeogr 16:24-33 doi:10.1111/j.1466-8238.2006.00258.x. https://doi.org/10.1111/j.1466-8238.2006.00258.x

Forman, R (2014) Urban Ecology: Science of Cities. Cambridge University Press, New York. Gillman, CA, \& Irschick, DJ (2013) Foils of flexion: the effects of perch compliance on lizard locomotion and perch choice in the wild. Funct Ecol 27:374-381.

http://doi.org/10.1111/1365-2435.12063 
425 Gunderson AR, \& Leal M (2012) Geographic variation in vulnerability to climate warming in a

426

427

428

429

430

431

432

433

434

435

436

437

438

439

440

441

442

443

444

445

446

447

tropical Caribbean lizard. Funct Ecol 26:783-793. https://doi.org/10.1111/j.1365-

2435.2012.01987.x

Hadfield JD (2010) MCMC methods for multi-response generalized linear mixed models: the MCMCglmm R package. J Stat Softw 33:1-22. http://doi.org/10.18637/jss.v033.i02

Hobbs, RJ, Arico, S, Aronson, J, Baron, JS, Bridgewater, P, Cramer, VA, et al. (2006) Novel ecosystems: Theoretical and management aspects of the new ecological world order. Glob Ecol Biogeogr 15:1-7. https://doi.org/10.1111/j.1466-822X.2006.00212.x

Holt RD, Barfield M, \& Gomulkiewicz R (2005) Theories of niche conservatism and evolution. In: Sax DF, Stachowicz JJ, \& Gaines SD (eds) Species invasions: insights into ecology, evolution, and biogeography. Sinauer Associates Incorporated Sunderland, MA, pp 259290.

Irschick DJ, Carlisle E, Elstrott J, Ramos M, Buckley C, Vanhooydonck B, ... Herrel A (2005a) A comparison of habitat use, morphology, clinging performance and escape behaviour among two divergent green anole lizard (Anolis carolinensis) populations. Biol J Linn Soc 85:223-234. https://doi.org/10.1111/j.1095-8312.2005.00487.x

Irschick, DJ, \& Higham, TE (2016) Animal Athletes: An ecological and evolutionary approach. Oxford University Press.

Irschick DJ, \& Losos JB (1998) A comparative analysis of the ecological significance of maximal locomotor performance in Caribbean Anolis lizards. Evolution 52:219-226. https://doi.org/10.2307/2410937

Irschick DJ, Vanhooydonck B, Herrel A, \& Meyers J (2005b) Intraspecific correlations among morphology, performance and habitat use within a green anole lizard (Anolis carolinensis) 
population. Biol J Linn Soc 85:211-221. https://doi.org/10.1111/j.1095-8312.2005.00486.x

Irschick DJ, \& Losos JB (1999) Do lizards avoid habitats in which performance is submaximal? The relationship between sprinting capabilities and structural habitat use in caribbean anoles. Am Nat 154:293-305. https://doi.org/10.1086/303239

Johnson MA, Kirby R, Wang S, \& Losos JB (2006) What drives variation in habitat use by Anolis lizards: Habitat availability or selectivity? Can J Zool 84:877-886. https://doi.org/10.1139/Z06-068

Johnson MA, Revell LJ, \& Losos JB (2010) Behavioral convergence and adaptive radiation: Effects of habitat use on territorial behavior in Anolis lizards. Evolution 64:1151-1159. https://doi.org/10.1111/j.1558-5646.2009.00881.x

Kolbe JJ, Battles AC, \& Avilés-Rodríguez KJ (2016a). City slickers: poor performance does not deter Anolis lizards from using artificial substrates in human-modified habitats. Funct Ecol 30:1418-1429. https://doi.org/10.1111/1365-2435.12607

Kolbe, JJ, Glor, RE, Schettino, LR, Lara, AC, Larson, A, \& Losos, JB (2004) Genetic variation increases during biological invasion by a Cuban lizard. Nautre 431:177-181. https://doi.org/10.1038/nature02807

Kolbe JJ, Glor RE, Schettino LR, Lara AC, Larson A, \& Losos JB (2007) Multiple sources, admixture, and genetic variation in introduced Anolis lizard populations. Conserv Biol 21:1612-1625. https://doi.org/10.1111/j.1523-1739.2007.00826.x

Kolbe JJ, VanMiddlesworth P, Battles AC, Stroud JT, Buffum B, Forman RTT, \& Losos JB (2016b) Determinants of spread in an urban landscape by an introduced lizard. Landscape Ecol 31:1795-1813. https://doi.org/10.1007/s10980-016-0362-1

Kowarik, I (2011) Novel urban ecosystems, biodiversity, and conservation. Environ Pollut 
472 Lapiedra O, Chejanovski Z, Kolbe JJ (2017) Urbanization and biological invasion shape animal personalities. Glob Change Biol 23:592-603. https://doi.org/10.1111/gcb.13395

474 Losos, J (2009) Lizards in an evolutionary tree: ecology and adaptive radiation of anoles (Vol.

475

Lowry H, Lill A, \& Wong BM (2013) Behavioral responses of wildlife to urban environments.

Losos JB, \& Irschick DJ (1996) The effect of perch diameter on escape behaviour of Anolis lizards : laboratory predictions and field tests. Anim Behav 51:593-602. https://doi.org/10.1006/anbe.1996.0063

Losos JB, \& Sinervo B (1989) The effects of morphology and perch diameter on sprint performance of Anolis lizards. J Exp Biol 145:23-30. Retrieved from http://jeb.biologists.org/content/145/1/23.abstract Biol Rev 88:537-549. http://doi.org/10.1111/brv.12012

Lynch, M, \& Lande, R (1993) Evolution and extinction in response to environmental change. In Karieva, M., Kingsolver, J. G., \& Huey, R. B. (Eds), Biotic Interactions and Global Change (pp. 234-250).

Marnocha E, Pollinger J, \& Smith TB (2011) Human-induced morphological shifts in an island lizard. Evol Appl 4:388-396. https://doi.org/10.1111/j.1752-4571.2010.00170.x

McDonnell MJ, \& Hahs AK (2015) Adaptation and adaptedness of organisms to urban environments. Annu Rev Ecol Evol S 46:261-280. https://doi.org/10.1146/annurev-ecolsys$112414-054258$

McDonnell MJ, \& Pickett STA (1990) Ecosystem structure and function along urban-rural gradients: an unexploited opportunity for ecology Ecology 71:1232-1237. 
https://doi.org/10.2307/1938259

McDonnell MJ, \& Pickett STA (1991) Comparative analyses of ecosystems along gradients of urbanization: opportunities and limitations. Comparative Anal Ecosyst. Springer New York $351-355$.

McKinney, ML, \& Lockwood, JL (1999) Biotic homogenization: A few winners replacing many losers in the next mass extinction. Trends Ecol and Evol 14:450-453. https://doi.org/10.1016/S0169-5347(99)01679-1

Nemeth E, \& Brumm H (2009) Blackbirds sing higher-pitched songs in cities: adaptation to habitat acoustics or side-effect of urbanization? An Behav 78:637-641. https://doi.org/10.1016/j.anbehav.2009.06.016

Oro D, Genovart M, Tavecchia G, Fowler MS, \& Martínex-Abraín A (2013) Ecological and evolutionary implications of food subsidies from humans. Ecol Lett 16:1501-1514. https://doi.org/10.1111/ele.12187

Palumbi, SR (2001) Humans as the world's greatest evolutionary force. Science 293:1786-1790. https://doi.org/10.1126/science.293.5536.1786

Pearman PB, Guisan A, Broennimann O, \& Randin CF (2008) Niche dynamics in space and time. Trends Ecol Evol 23:149-158. https://doi.org/10.1016/j.tree.2007.11.005

Penick, CA, Savage, AM, \& Dunn, RR (2015) Stable isotopes reveal links between human food inputs and urban ant diets. Proc Royal Soc B 282: 20142608. https://doi.org/10.1098/rspb.2014.2608

Powell, R, Henderson, RW, Adler, K, \& Dundee, HA (1996) An annotated checklist of West Indian amphibians and reptiles. Contributions to West Indian Herpetology: A Tribute to Albert Schwartz, 51-93. 
517 R Core Team (2014) R: a language and environment for statistical computing. R Foundation for 518 Statistical Computing, Vienna, Austria. Available at: http://www.R-project.org/

519 Rodríguez-Robles JA, Leal M, \& Losos JB (2005) Habitat selection by the Puerto Rican yellow520 chinned anole, Anolis gundlachi. Can J Zool 83:983-988. https://doi.org/10.1139/Z05-082

521 Salzburg MA (1984) Anolis sagrei and Anolis cristatellus in southern Florida: a case study in

522 interspecific competition. Ecology 65:14-19. https://doi.org/10.2307/1939453

523 Schlaepfer MA, Sherman PW, Blossey B, \& Runge MC (2005) Introduced species as

524 evolutionary traps. Ecol Lett 8:241-246. https://doi.org/10.1111/j.1461-0248.2005.00730.x

525 Shochat E, Warren PS, Faeth SH, McIntyre NE, \& Hope D (2006) From patterns to emerging

526 processes in mechanistic urban ecology. Trends Ecol Evol 21:186-191.

527 https://doi.org/10.1016/j.tree.2005.11.019

528 Sih, A, Ferrari, MCO, \& Harris, DJ (2011) Evolution and behavioural responses to human-

529 induced rapid environmental change. Evol Appl 4:367-387. https://doi.org/10.1111/j.1752-

$530 \quad 4571.2010 .00166 . x$

531 Sol D, Lapiedra O, \& González-Lagos C (2013) Behavioural adjustments for a life in the city.

532 An Behav 85:1101-1112. https://doi.org/10.1016/j.anbehav.2013.01.023

533 Thompson, JN (2013) Relentless Evolution. University of Chicago Press, Chicago

534 Tingley R, Vallinoto M, Sequeira F, \& Kearney MR (2014) Realized niche shift during a global

535 biological invasion. PNAS 111:10233-10238. https://doi.org/10.1073/pnas.1405766111

536 Weaving MJ, White JG, Isaac B, Rendall AR, \& Cooke R (2016) Adaptation to urban 537 environments promotes high reproductive success in the tawny frogmouth (Podargus 538 strigoides), an endemic nocturnal bird species. Landscape Urban Plan 150:87-95.

539 https://doi.org/10.1016/j.landurbplan.2016.03.001 
540 Wilson, LD, \& Porras, L (1983) The ecological impact of man of the south Florida

541 Herpetofauna. Lawrence: University of Kansas: Museum of Natural History.

542 Winchell KM, Reynolds RG, Prado-Irwin SR, Puente-Rolón AR, \& Revell LJ (2016) Phenotypic

543 shifts in urban areas in the tropical lizard Anolis cristatellus. Evolution 70:1009-1022.

$544 \quad$ https://doi.org/10.1111/evo.12925

545 Wingfield JC, Kelley JP, Angelier F, Chastel O, Lei F, Lynn SE, et al. (2011) Organism-

546 environment interactions in a changing world: A mechanistic approach. J of Ornithol

547 152:279-288. https://doi.org/10.1007/s10336-011-0668-3

548 Wright, AN (2009) Niche breadth, disturbance specialization, and behavioral flexibility in an

549 invasive lizard, Anolis sagrei. PhD dissertation, Department of Biology, University of

550 California: Davis, Davis, California. 